\title{
Development of Creative Behavior Observation Form: A Study on Validity and Reliability ${ }^{*}$
}

\author{
Zeynep Dere ${ }^{1, *}$, Esra Ömeroğlu ${ }^{2}$ \\ ${ }^{1}$ Primary Education, Division of Preschool Education, Bozok University, Turkey \\ ${ }^{2}$ Primary Education, Division of Preschool Education, Gazi University, Turkey
}

Copyright $\odot 2018$ by authors, all rights reserved. Authors agree that this article remains permanently open access under the terms of the Creative Commons Attribution License 4.0 International License

\begin{abstract}
This study, Creative Behavior Observation Form was developed to assess creativity of the children. While the study group on the reliability and validity of Creative Behavior Observation Form was being developed, 257 children in total who were at the ages of 5-6 were used as samples with stratified sampling method. Content Validity Index (CVI) and Confirmatory Factor Analysis (CFA) were applied in order to measure validity of Creative Behavior Observation Form. Test-retest method was used in order to determine if Creative Behavior Observation Form has reliable measurements in time. This study concludes with recommendations for the applicators, researchers and teachers who will use Creative Behavior Observation Form as an instrument to develop creativity of preschool children.
\end{abstract}

Keywords Preschool Education, Creativity, Creative Behavior Observation Form

\section{Introduction}

When creativity performance of an individual is considered, it is seen that highest level of creativity and highest number of creative behavior exist in pre-school period. Children can display their creativity in various activities during the day. It is significant to observe creativity within a process in the course of early childhood. Torrance [1] says creativity begins during pre-school period and gradually decreases in later years. Therefore, educators are expected to attach necessary importance to creativity and utilize it in the classroom. Planned activities should support and develop creativity of the children.

According to Torrance [2], creativity is the process of developing a hypothesis where challenges, problems, deficiencies and flaws are detected and possible ways to overcome the problems are sought and finally the problems are solved. Steps in the creative process have quite a good system. Torrance [1] tells cases of deficiency in an individual, seeking for a way out or failure to solve a problem lead to emergence of creativity. Rosnick [3] address exploring new things, discussing on a subject, trying to repeat the results, in-depth analysis of the advantages and the disadvantages of the results develop creativity. Individuals, being exposed to certain stages within all these processes, utilize their real creativity and generate their product.

$[4,5]$ Individual uses 2 types of thinking methods in creative thinking process. First one is convergent thinking, and the other one is divergent thinking. Convergent thinking is the case when a single answer is provided for a question or problem. It is divergent thinking when a problem is provided with many answers. Edwards [6] utter providing the children with appropriate opportunities to think, in a way where these processes moves along consistently with each other, will improve their creativity. Educators who appreciate thinking processes in the education of the children, try to improve himself/herself, understand the creativity theories and follow the developments in the field of creativity contribute positively to the children's creativity. [7] During creative process, an individual can change his/her mind until the product satisfies him/her, can make new trials and change his/her perspective until s/he gets what $\mathrm{s} /$ he wants. $\mathrm{S} /$ he reaches a satisfactory solution at the end of the attempts. Every product is acquired as a result of creative thinking. [8, 9]All behaviors, expressions and products of children during the activities should be assessed according to the criteria of fluency, flexibility, originality and elaboration.

Fluency: Edwards [6] mention all of the acts performed orally or non-orally, concerning the ideas and thoughts. In order to observe the fluency, simple questions are asked and the evaluation is conducted according to the number of answers. [10]It is the total sum of different ideas, in other words, it is equivalent with the consecutive generation of the products. [11]The fluency dimension is assessed in accordance with the answers of the questions such as; What are the things you can think of as a square? Say the names of the edible white materials that come to your mind? What 
are the benefits of bricks?

Flexibility: Edwards [6] put it is when the person can see sudden changes and leaves the traditional method of problem solving. Flexibility is displayed in creative behaviors in two ways. First one is cognitive flexibility. Cognitive flexibility facilitates problem solving. The second one is behavioral flexibility. [11] Flexibility is the ability of individual for transition from a conceptive theme or event to another without difficulty. Different conception tests are used for measuring flexibility. Different conception does not have the same meaning with creativity, but different conception tests are very useful for testing the creative thinking. Researches indicate that the different conception tests are the most effective method for the evaluation of flexibility.

Originality: According to Kaufmann [12] originality means offering different solutions for a problem. If the solution is the same with someone else's, then there is no originality. [13] Originality is novelty and emerges with extraordinary answers. The concept of originality is closely related with "novelty", which is a major characteristic of many standard definitions of creativity. A new product or an expression can be considered as original. Novelty of products and expressions are indispensable elements of creativity. Guilford [14] tells if the product is different from the ones in the past, if not ordinary, we can call it as new. The product should be generated a least in a different time or place. The product which is generated genuinely can be called original.

Elaboration: Feldman [15] description of a thought in detail, its elaboration and improvement is a distinct ability in creativity. According to Edwards [6] beautification a product means adding an extra detail or making a final touch Children usually tend to elaborate on the ideas.

[13] When a child makes a paper chain, s/he can immediately attach it to the ribbon of a gift box as a decoration. Children develop ideas in this way and they elaborate the ideas for which they developed to generate a different product. [16] After an incomplete plan is given to the individual and $\mathrm{s} / \mathrm{he}$ is asked to list all the steps for the operation of the plan, the answers can provide information about the elaboration factor. It is the ability to complete and add details to an incomplete thought or any thought.

$[17,18,19,20,21,22,23]$ In order to identify the creativity of pre-school children, the following measurement instruments have been developed: Torrance Tests of Creative Thinking- TCTT by Torrance (1968), Creativity Assessment Packet by Williams (1980), Thinking Creatively in Action and Movement's Test TCAM by Torrance (1981), Preschool and Kindergarten Interest Descriptor-PRIDE by Rimm (1983), Creativity Evaluation of Potential Creativity-EPoC by Lubart (2009), Integrated Creativity Test for Preschoolers by Lee and Lee (2002), Pedagogical Framework for Creative Practices by Cheung (2013).

As for the measuring instruments developed for the creativity of pre-school children, common points are they are all based on the drawing abilities and immediate performances of children are evaluated. However, evaluation of the creativity according to the immediate performance of pre-school children may bring a restrictive view to creativity. Creativity process of children can be assessed by observing their natural performances. There are no instruments to identify creativity basing on the observation data.

It is very important to evaluate creativity in preschool period. Creativity early childhood can be observed within a period of time. Children are different activities throughout the day they can reveal their creativity. However, when studies are carried out it is seen that there is no observation form in which children's creative behaviors are observed in the process. For this reason, children's creative it is important to develop an observation form in this study. This study focuses on the development of Creative Behavior Observation Form.

\section{Methodology}

This research focuses on a study to develop an observation form. Methodological research method was used in order to perform validity and reliability study of Creative Behavior Observation Form developed for 5-6 year old children. Özdamar [24] found Methodological researches were carried out for theoretical research, theory development, theorem justification, development of an instrument or a model.

The number of children attending pre-schools within primary schools in Ankara is 32.897 during 2012-2013 education year. All of these children constitute the universe. In order to identify the sample of validity and reliability study for Creative Behavior Observation Form, samples were selected with stratified sampling method, in the range of $5 \%$ for sensitivity and $95 \%$ for confidence interval, from seven different central districts. Sampling consisted of 257 children in total; 40 from Yenimahalle district, 40 from Mamak district, 39 from Keçiören district, 35 from Etimesgut district, 38 from Sincan district, 37 from Çankaya district and 28 from Altındağ district. In the validity reliability study of the form, 55 of 58-66 month-old children are male and 53 are female, 76 of 67-72 month-old children are male and 73 are female. 131 of the total 257 children of 58-72 month-olds are male and 126 are female.

Formation of Creative Behavior Observation Form: Initially, literature was reviewed on this subject while establishing Creative Behavior Observation Form, which was developed for assessment of 5-6 year-old children's creativity. Creativity theorems of Torrance, Guilford and Kaufmann were analyzed; characteristics of the creative person that is commonly specified by each of them and creativity-related scales were examined. Overlapping behaviors in the scales and the ones observed in children 
were collected under the same heading. In this way, relying on the creativity processes, an observation form with 25 items were established with Flexibility, Fluency, Originality and Elaboration dimensions. This 25-item observation form was presented to two measuring and evaluation experts and two field experts, and they were asked to analyze them. After receiving feedback from the experts, Creative Behavior Observation Form has been finalized in totally 26 items, which are 6 items to be observed in the Flexibility dimension, 8 items to be observed in the Fluency dimension, 6 items to be observed in the Originality dimension and 5 items in the Elaboration dimension.

Formation of the Creative Behavior Observation Form User Guide: Creative Behavior Observation Form User Guide was created in order to define under which circumstances 26 behaviors in the Creative Behavior Observation Form will be observed and how these observed behaviors will be assessed. Examples were given about assessment of the items in the form and it was explained when the children can pass the items. To finalize the Creative Behavior Observation Form User Guide, it was presented to two measuring and evaluation experts, besides two field experts; and necessary amendments were made.

Composition of the Creative Behavior Observation Form Activities: Creative Behavior Observation Form Activities was developed to observe the activities of creative children. Composing of four different activities, Creative Behavior Observation Form Activities were planned to carry out one activity for each day. During the development of activities, it was paid attention that the behaviors in the observation form are included in the activities and that they are observable. For the evaluation of activities after their completion, opinions of four experts, who are two field experts, two measuring and evaluation experts, were taken. Necessary amendments were made in accordance with the recommendations.

Creative Behavior Observation Form Activity Cards: There are 50 photo cards in four of the Creative Behavior Observation Form Activities for revealing the creativity of children. Activity cards were presented to two field experts and necessary amendments were made.

Pilot Implementation of the Creative Behavior Observation Form: In order to try the applicability of the 26-item Creative Behavior Observation Form, a pilot application was performed with children. 20 children aged 5-6 were examined for this purpose. At the end of pilot application, it was concluded that items and activities of the Creative Behavior Observation Form are applicable.

Video camera was mounted on a location from where all children could be seen during the activities in order to record their behaviors. When the activities in all schools and classes were completed, videotapes were transferred to a CD. Data in DVD format were backed up in an external memory. Exercises that were recorded by the camera were watched by the researcher in the end. Creative behaviors of a child in an activity were marked on an observation form. Four observation forms were filled in total for four different activities of a child.

The following analyses were made with the data obtained from the applications in order to provide a proof forthe validity and reliability of Creative Behavior Observation Form:

- Content Validity of the Creative Behavior Observation Form: It was created through the views of the expert and literature review.

- Construct Validity of the Creative Behavior Observation Form: It was provided by Affirmative Factor Analysis.

- Cronbach's Alfa reliability was calculated to ensure the Internal Consistency Reliability.

- Reliability coefficient was calculated with regard to Test- ReTest reliability.

\section{Results}

The Creative Behavior Observation Form was developed by the researcher in order to measure creativity in children aged 5-6 in terms of flexibility, fluency, originality and elaboration dimensions. The Creative Behavior Observation form involves 26 items and four dimensions. There are seven items in the flexibility, eight items in the fluency, six items in the originality and five items in the elaboration dimensions, respectively.

The Creative Behavior Observation Form consists of a set including a user manual, creativity observation form activities and 20 problem solution, 20 animal and 10 story cards. To determine the cases in which the 26 behaviors included in the Creative Behavior Observation Form are observed, the user manual was developed by the researcher. The manual specifies for which purpose, in which context and under which conditions observations will be made. In the manual, there are also behaviors samples related to the behaviors that will be observed. While the Creative Behavior Observation Form is filled out, the user manual is used to decide whether the child passes an item or not. The items in the user manual are separately developed as Flexibility (FLX), Fluency (FC), Originality (O) and Elaboration (E). The behavior in the item 'sets up an activity (game) with friends' is developed to observe the child's production of different ideas in his/her activity and is included in the flexibility dimension. For the item 'sets up an activity through initiating interaction with other children', the child can pass on condition that s/he does one or a few of the behavior(s) including ' $\mathrm{s} / \mathrm{he}$ starts the game through going to a friend and uttering a sentence, s/he asks unusual questions, the activity s/he sets up has a purpose and a logical structure, makes explorations in the activity s/he sets up, the activity s/he sets up has a beginning and end, the result of his/her activity can be transferred to other 
activities, and the activity s/he sets up attracts other children's attention'. Structured activities are developed to observe the 26 items in the observation form. While the child implements his/her activity, observed behaviors are video-recorded through a camera and then, marked in the Creative Behavior Observation Form. For instance, after the child looks at the dog card and imitates how it walks, $\mathrm{s} / \mathrm{he}$ is asked to think and show how else it can walk. To make an evaluation here, the behaviors that the child does in this activity are marked across the appropriate item in the observation form.

Creative Behavior Observation Form is assessed by watching application of four activities successively and as a group activity for one child. Average of the behaviors observed in four activities is calculated. It is possible to comment on how creative the child in comparison to other children is by looking at the averages in all dimensions. One observation form is filled for each activity of one child. Totally four observation forms are filled for four activities. Child, in the activity, is graded depending on how many times s/he performed the items in the Creative Behavior Observation Form, as the following: Never: 0, Once: 1, 2-3 times: 2, 4-5 times: 3, 6 and more times: 4 .

\subsection{Content Validity of the Creative Behavior Observation Form}

Views of the experts were taken in order to determine content validity of Creative Behavior Observation Form. Content validity ratio of each item was calculated while assessing the views of the experts. Later content validity index was prepared based on the average content validity ratios (CVR). Yurdugül [25] says this index is used to determine if each item is deemed necessary by the experts. Four experts were assigned for the views of the exports on the Creative Behavior Observation Form; two as measurement and assessment experts and two as domain experts. Experts were asked to assess the items in terms of compliance with the purpose of the research, clarity and intelligibility. They were allowed to deduct, amend or add the parts when they find it necessary. Büyüköztürk [26] shows one of the methods to ensure content validity is asking views of the experts. Views of the experts are taken through a form and after the assessment items with an agreement of $\% 68$ are maintained in the instrument. Items which have $80 \%$ criticisms can be maintained after corrected. Yurdugül [25] says taking into account that there are four experts, measurement with content validity index ratio higher than 0.99 are regarded to ensure content validity. Content validity index ratio of observation form was computed as 1.00 since content validity ratio for all the items in all observation forms are 1.00 . These ratios mean that all the items in the observation form are necessary and they ensure content validity. Following the content validity, construct validity was sought in the Creative Behavior Observation Form.

\subsubsection{Confirmatory Factor Analysis (CFA)}

Data of reliability studies were collected by the researcher through "Creative Behavior Observation Form". There are four factors and items in the form. Seven items form "flexibility" factor, eight items "fluency" factors, six items "originality" factors and five items "elaboration" factors. First level confirmatory factor analysis examined whether construct of the measurement with four factors and 26 items were confirmed. Confirmatory Factor Analysis intends to assess to what extend a factorial model comprising of factors with plenty observed variables (latent variables) is compatible with real data.

$[27,28]$ The model to be studied may define a construct which is defined relying on data of an empirical study or developed on a theory. Many fit indices are used in order to assess validity of the model in Confirmatory Factor Analysis. Most commonly used indices used for assessment of validity are as follows; the Chi-Square Fit Test, Root Mean Square Error of Approximation, Comparative Fit Index, Normed Fit Index, Adjusted Goodness of Fit Index. During Confirmatory Factor Analysis of the Creative Behavior Observation Form, Chi-Square Goodness $\left(\chi^{2}\right)$, Root Mean Square Error of Approximation (RMSEA), Comparative Fit Index (CFI), Non-Normed Fit Index (NNFI), Normed Fit Index (NFI) and Goodness of Fit Index (GFI) were used. Items with statistically non-significant $t$ values were examined in the first CFA. Results showed that there are no items which have statistically non-significant $t$ value. 


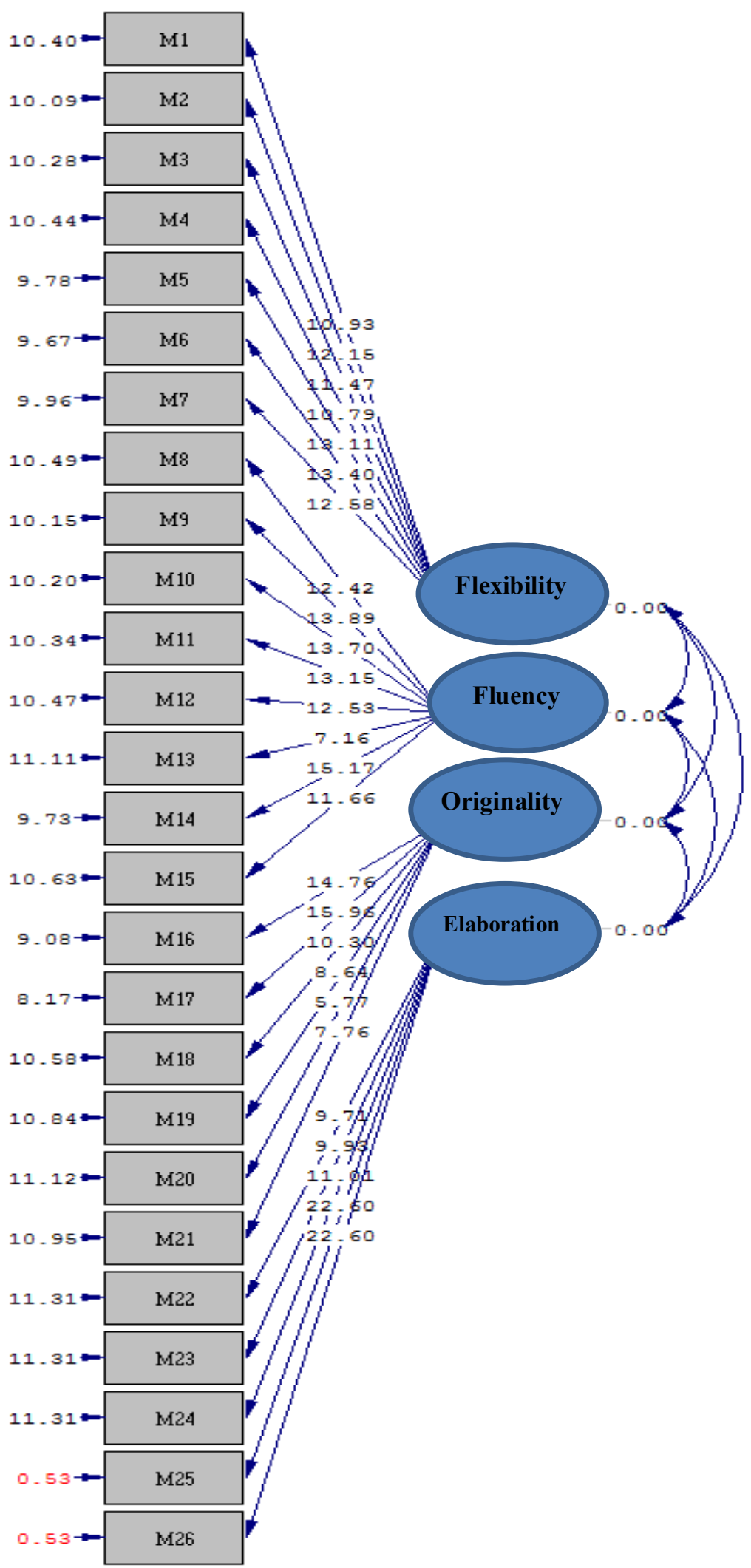

Figure 1. Path Diagram of Creative Behavior Observation Form 
It is seen in Figure 1 that final version of Creative Behavior Observation Form consists of 26 items and four factors. Flexibility, the first factor, has seven items, fluency factor has eight items, originality factor has six items and elaboration factor has five items.

Table 1. Fit Indices of Creative Behavior Observation Form

\begin{tabular}{|c|c|}
\hline Statistics & Values \\
\hline $\mathrm{x}^{2}$ & 1162.16 \\
\hline $\mathrm{X}^{2} / \mathrm{sd}$ & 3.97 \\
\hline $\mathrm{CFI}$ & 0.94 \\
\hline $\mathrm{NNFI}$ & 0.94 \\
\hline $\mathrm{NFI}$ & 0.92 \\
\hline
\end{tabular}

As seen in Table 1, there are critical values concerning goodness of fit indices in order to assess fitness of Creative Behavior Observation Form. $\mathrm{X}^{2} / \mathrm{sd}$ ratio is less than 5 and $\mathrm{CFI} / \mathrm{NNFI}$ value is higher than 0.90 , which implies fitness in the observation form. Sümer [27] says measurement model indicates perfect fitness in case that observed values range as follows: $\mathrm{X}^{2} / \mathrm{d}<3 ; 0<\mathrm{RMSEA}<0.05 ; 0.97 \leq \mathrm{NNFI} \leq 1$; $0.97 \leq \mathrm{CFI} \leq 1 ; 0.95 \leq \mathrm{GFI} \leq 1$ and $0.95 \leq \mathrm{NFI} \leq 1$ and acceptable fitness in case observed values range as follows: $4<\mathrm{X}^{2} / \mathrm{d}<5$; $0.05<\mathrm{RMSEA}<0.08 ; \quad 0.95 \leq \mathrm{NNFI} \leq 0.97 ; \quad 0.95 \leq \mathrm{CFI} \leq 0.97$; $0.90 \leq \mathrm{GFI} \leq 0.95$ and $0.90 \leq \mathrm{NFI} \leq 0.95$.

When coefficients which imply the relationship between observed variables and factors of the model with fourfactorial construct in the Creative Behavior Observation Form are taken into account, it can be concluded that $\mathrm{X}^{2} / \mathrm{sd}, \mathrm{CFI}$ and NNFI fit indices are at sufficient level. Fitness statistics calculated through Confirmatory Factor Analysis come up with the results that pre-established four-factorial construct of the Creative Behavior Observation Form, namely flexibility, fluency, originality and elaboration, show high compliance in general with the collected data.

Table 2. Results of regression and t values belonging to Confirmatory Factor Analysis of Creative Behavior

\begin{tabular}{|c|c|c|c|c|c|}
\hline Items & $\begin{array}{l}\text { Regression } \\
\text { Values }\end{array}$ & $\mathrm{t}$ values & Items & $\begin{array}{l}\text { Regression } \\
\text { Values }\end{array}$ & $\mathrm{t}$ values \\
\hline $\begin{array}{l}\text { I.1. Flexibility: Sets up an activity (game) with } \\
\text { friends }\end{array}$ & 0.18 & 10.93 & $\begin{array}{l}\text { I.14. Fluency: Establishes cognitive } \\
\text { relationships (part-whole, reason-result, } \\
\text { pattern relationships) }\end{array}$ & 0.32 & 15.17 \\
\hline $\begin{array}{l}\text { I.2. Flexibility: Takes on group leadership } \\
\text { while playing with friends }\end{array}$ & 0.22 & 12.15 & I.15. Fluency: Draws analogies & 0.25 & 11.66 \\
\hline $\begin{array}{l}\text { I.3. Flexibility: Makes task distributions to } \\
\text { friends while doing an activity }\end{array}$ & 0.18 & 11.47 & $\begin{array}{l}\text { I.16. Originality: Is willing to spontaneously } \\
\text { start an activity }\end{array}$ & 0.33 & 14.76 \\
\hline $\begin{array}{l}\text { I.4. Flexibility: Uses the classroom materials in } \\
\text { accordance with their purposes without the } \\
\text { teacher guidance }\end{array}$ & 0.17 & 10.79 & $\begin{array}{l}\text { I.17. Originality: Finds different solutions } \\
\text { for a problem }\end{array}$ & 0.33 & 15.96 \\
\hline $\begin{array}{l}\text { I.5. Flexibility: Uses the materials for purposes } \\
\text { different from their functions }\end{array}$ & 0.24 & 13.11 & I.18. Originality: Asks unusual questions & 0.27 & 10.30 \\
\hline $\begin{array}{l}\text { I.6. Flexibility: Acts in accordance with a } \\
\text { stimulus (music, verbal stimulus, visual } \\
\text { stimulus) }\end{array}$ & 0.38 & 13.40 & I.19. Originality: Creates an original product & 0.30 & 8.64 \\
\hline $\begin{array}{l}\text { I.7. Flexibility: Organizes the materials given } \\
\text { to him/her (classifies, ranges, distinguishes, } \\
\text { groups) }\end{array}$ & 0.28 & 12.58 & $\begin{array}{l}\text { I.20. Originality: Spontaneously does } \\
\text { research }\end{array}$ & 0.12 & 5.77 \\
\hline I.8. Fluency: Focuses on an activity & 0.34 & 12.42 & $\begin{array}{l}\text { I.21. Originality: Spontaneously does } \\
\text { demonstrations }\end{array}$ & 0.15 & 7.76 \\
\hline I.9. Fluency: Searches how objects work & 0.33 & 13.89 & $\begin{array}{l}\text { I.22. Elaboration: Creates an elaborated } \\
\text { product }\end{array}$ & 0.24 & 9.71 \\
\hline $\begin{array}{l}\text { I.10. Fluency: Shows patience to solve a } \\
\text { problem situation }\end{array}$ & 0.35 & 13.70 & $\begin{array}{l}\text { I.23. Elaboration: Spontaneously makes } \\
\text { additions to an existing product }\end{array}$ & 0.27 & 9.93 \\
\hline $\begin{array}{l}\text { I.11. Fluency: Creates a new product upon } \\
\text { being affected by a stimulus }\end{array}$ & 0.41 & 13.70 & $\begin{array}{l}\text { I.24. Elaboration: Uses the materials in the } \\
\text { classroom together while performing a task }\end{array}$ & 0.27 & 11.01 \\
\hline I.12. Fluency: Uses words fluently & 0.29 & 12.53 & $\begin{array}{l}\text { I.25. Elaboration: Searches how objects } \\
\text { work through elaboration }\end{array}$ & 0.41 & 22.60 \\
\hline I.13. Fluency: Gives imitations & 0.07 & 7.16 & $\begin{array}{l}\text { I.26. Elaboration: Uses the language in an } \\
\text { elaborated way while narrating the activities } \\
\text { and actions }\end{array}$ & 0.41 & 22.60 \\
\hline
\end{tabular}


In Table 2 when $t$ values are considered in order to understand if each value in the model is statistically significant, it is seen that all values are higher than the critical value of 1.96. Based on this fact, it was determined that all $\mathrm{t}$ values are significant confirming four-factorial model. Taking into account the coefficients between the factors and observed variables of the model which demonstrates factorial construct of the Creative Behavior Observation Form within the context of Table 2 and data in Table 2, it is concluded that all coefficients are at sufficient level. It was also found out that goodness of fit values computed through DFA significantly and statistically support pre-established four-factorial construct of the observation form and have fit the construct.

According to the results, values obtained concerning the study model show that modeling factorial construct has been confirmed in scope of standard fitness values. Validity study of the Observation Form established four dimensions of the Creative Behavior Observation Form; namely, Flexibility, Fluency, Originality and Elaboration. Flexibility dimension has seven items, fluency dimension has eight items, originality dimension has six items and elaboration factor has five items.

\subsection{Reliability Study of Creative Behavior Observation Form}

Reliability coefficient for Cronbach's alpha internal consistency and reliability coefficient for test-retest were computed in order to ensure reliability of Creative Behavior Observation Form. Reliability means that individuals give the same response to the test items in each case. According to Büyüköztürk [26] there are two criteria here; "consistency between mean values obtained at different times" and "consistency between mean values obtained at the same time". It is possible to use test- retest reliability and Cronbach's alpha reliability to ensure reliability of the measurement instruments.

Cronbach's Alpha reliability coefficient was computed in order to determine reliability of the Creative Behavior
Observation Form. Coefficient of flexibility, the first factor, was computed as 0.85 ; fluency factor as 0.88 ; originality factor as 0.77; and elaboration factor as 0.87 . Tezbaşaran [29] tell overall coefficient for the Creative Behavior Observation Form was calculated as 0.94. In a Likert type scale, reliability coefficient should be close to 1 as much as possible to be regarded as reliable. According to the results, whole Creative Behavior Observation Form can be regarded to have high reliability level.

Test- retest analysis was performed after reliability coefficient of Creative Behavior Observation Form was checked and its reliability was confirmed.

\subsubsection{Reliability Coefficient in Terms of Test - Retest Reliability}

Test-retest method was used in order to determine if Creative Behavior Observation Form has performed reliable measurements in time. 60 of 257 children involved in the research were randomly selected for this purpose. Observation Form Activities were applied to these 60 children again after four weeks.

[30] Sampling size of at least 50 participants is recommended in order to determine test-retest reliability coefficient. Büyüköztürk [26] suggested sampling size is sufficient for Pearson correlation coefficient or independent samples t-test which is carried out in order to determine test-retest reliability coefficient. Furthermore, reliability of test-retest is justified by a correlation between mean values which are reached by applying a test to the same group twice at certain internals. Usually four week period is suggested as an internal between two applications T-test was used for the related samples and Pearson Product Moment Correlation Coefficient of the mean values obtained from both applications. Correlation coefficient is expected to be significant and close to 1 , and $t$ test results should be insignificant at .05 level. In other words, mean values obtained from both applications in the Creative Behavior Observation Form are expected to have insignificant differences and mean values be close to each other.

Table 3. T-test Results based on Mean Values of Test-Retest obtained from Mean Values of Creative Behavior Observation Form

\begin{tabular}{ccccccc}
\hline Group & $\mathrm{N}$ & $\overline{\boldsymbol{X}}$ & $\mathrm{SS}$ & $\mathrm{sd}$ & $\mathrm{t}$ & $\mathrm{p}$ \\
\hline First Application & 60 & 54.15 & 7.07 & 59 & & 1.05 \\
Second Application & 60 & 55.38 & 7.83 & & & .297 \\
\hline
\end{tabular}


According to Table 3, mean values of retest obtained from Creative Observation Form does not show any statistical differences; $\mathrm{t}(59)=1.05, \mathrm{p}>.05$.

Findings demonstrate that Creative Behavior Observation Form designed to assess creativity of five/six year old children is reliable in terms of internal consistency and can perform reliable measurement in terms of time.

\section{Conclusions}

Since CVR for all items in the observation form is 1.00 , CFA value of the observation form was calculated to be 1.00. These values mean that all the items in the observation form are necessary and content validity has been provided.

When the coefficients showing the relationship between observed variables and factors of the model based on four factors in Creative Behavior Observation Form is considered, it can be concluded that $\mathrm{X}^{2} / \mathrm{sd}=3.97, \mathrm{CFI}=0.94$ and $\mathrm{NNFI}=0.92$ fit indices in particular are at sufficient level.

Fit statistics computed with Confirmatory Factor Analysis come up with the results that pre-established four factorial construct of the Creative Behavior Observation Form, namely flexibility, fluency, originality and elaboration, has high fitness rate in line with the data collected in general.

$\mathrm{T}$ values of the Confirmatory Factor Analysis in the Creative Observation Form are higher than 1.96, the critical value. It was also concluded that goodness of fit values computed through DFA significantly support pre-established four-factorial construct of the observation form in terms of statistics and have fit the construct.

Cronbach's alpha reliability coefficient was calculated in order to determine reliability of the Creative Observation Form. Coefficient of flexibility, the first factor, was computed as 0.85 ; coefficient of fluency factor as 0.88 ; coefficient of originality factor as 0.77 ; and coefficient of elaboration factor as 0.87 . Coefficient for overall Creative Behavior Observation Form was calculated as 0.94. These results indicate that whole Creative Behaviour Observation Form has high reliability rate.

Test-retest method was used in order to determine if Creative Behavior Observation Form performed reliable measurement or not in time. Correlation coefficient was computed as 0.51 as a result of t-test. This coefficient is significant at .05 level and moderate. It is seen that mean values of the first and final applications obtained from the Creative Behavior Observation Form do not show statistical differences $t(59)=1.05, p>.05$. Results of the research indicate that Creative Behavior Observation Form is a valid and reliable instrument to assess creativity of the children.

Based on the results of the research, the following recommendations can be proposed in order to develop creativity of preschool children:

- Researchers and educators who wish to use Creative Behavior Observation Form are suggested to utilize all materials of the form without any missing parts.

- Further studies may continue with less number of children and qualitative research can be developed concerning creativity.

- Creative Behavior Observation Form was developed for preschool children in Ankara. Therefore, Creative Behavior Observation Form can be applied for the children living in different regions in further studies.

- Creative Behavior Observation Form is an observation tool prepared for preschool children. In further researched, it is recommended to study on different age groups such as primary school children, in addition to preschool children, by planning or adapting different activities.

- It is possible to develop a scale through which creativity of the children are assessed by the families during further studies on creativity.

- It will be beneficial to develop a measurement instrument which defines the attitudes and behaviors of the teachers concerning creativity.

\section{REFERENCES}

[1] E. P. Torrance. Creativity: Progress and Potential, Mcgraw-Hill Book Company, USA, 1964.

[2] E. P. Torrance. The millennium: a time for looking forward and looking back. The Journal of Secondary Gifted Education, Vol.15, No.1, 6-12, 2003.

[3] K. K. Rosnick. Perspectives on Creativity, United Kingdom, Cambridge Scholars Publishing, 2009.

[4] M. Mayesky. Creative Activities for Young Children, Delmar Cengage Learning, USA, 2009.

[5] D. A. Bernstein, P. W. Nash. Essentials of Psychology, Houghton Miffin Company, Boston, 2005.

[6] L. C. Edwards. The Creative Arts A Process Approach for Teachers and Children, Pearson Merrill Prentice Hall, New Jersey, 2006.

[7] C. Edwards, L. Gandini, G. Forman. The Reggio Emilia Approach Advanced Reflections, Ablex Publishing Corporation, USA, 1993.

[8] J. C. Kaufman, R. A. Beguetto. Beyond big and little: the four c model of creativity, Review of General Psychology, Vol. 13, 1-12, 2009.

[9] [9]. A. Antonietti. Enhancing creative analogies in primary school children, North American Journal of Psychology, Vol. 2, No. 2000, 75-84, 2000.

[10] R. J. Gerrig, P. G. Zimbardo. Psychology and Life, Pearson, 
USA, 2005.

[11] M. A. Runco, S. R. Pritzker, Encyclopedia of Creativity Volume I, Academic Press, London, 1999.

[12] G. Kaufmann. Understanding and Recognizing Creativity: The Emerge of a Discipline, Ablex Publishing Corporation, New Jersey, 1993.

[13] R. T. Isbell, S. C. Raines. Creativity and the Arts with Young Children. Thomson Delmar Learning, USA, 2003.

[14] J. P. Guilford. Creativity, Penguin, Harmondsworth, 1976.

[15] D. H. Feldman. Handbook of Creativity Cambridge University Press, United Kingdom, 1999.

[16] L. S. Almeidaa, L. P. Prieto, M. Ferrando, E. Oliveiraa, C. Ferrandiz. Torrance test of creative thinking: the question of its construct validity. Thinking Skills and Creativity, Vol. 2, No. 2008, 53-58, 2008.

[17] E. P. Torrance. Torrance Tests of Creative Thinking Directions Manual and Scoring Guide, Personnel Press, New Jersey, 1968.

[18] F. Williams. Creativity Assessment Packet Examiner's Manual, Pro-Ed Inc, Texas, 1980

[19] E. Zachopoulou, A. Makri, E. Pollatou, Evaluation of children's creativity: psychometric properties of Torrance's 'thinking creatively in action and movement' test, Early Child Development and Care, Vol.176, No.3, 317-328, 2009.

[20] PRIDE, Preschool and Kindergarten Interest Descriptor, Online available from www.sylviarimm.com/cii.html.

[21] EPoC, Evaluation of Potential Creativity, Online available from http://www.epoctest.net/en/index.php/item/34-epoc-english.

[22] K. Lee. The relationship between creative thinking ability and creative personality of preschoolers, International Education Journal, Vol. 6, No. 2, 194-199, 2005.

[23] R. H. P. Cheung. Exploring the use of the pedagogical framework for creative practice in preschool settings: a phenomenological approach. Thinking Skills and Creativity, Vol. 10, No. 2013, 133-142, 2013.

[24] K. Ozdamar. Modern Scientific Research Methodologies, Kaan Press, Eskisehir, 2003.

[25] H. Yurdugul, Use of Scope Validity Index for Scope Validity during Scale Development Studies. 14. National Congress for Educational Sciences, House of Denizli University, 2005.

[26] Buyukozturk, S. Handbook for Data Analysis in Social Sciences. Statistical Research Design SPSS Implementations and Interpretation, Pegem A Press, Ankara, 2012.

[27] N. Sumer. Structural equity models: basic concepts and sample applications, Turkish Psychologists Press, Vol. 3, No.6, 49-74, 2000.

[28] D. A. Cole. Utility of confirmatory factor analysis in test validation research. Journal of Consulting and Clinical Psychology, Vol. 55, 584-594, 1987.

[29] A. Tezbasaran. Likert-Scale Development Guide, Association of Turkish Psychologists Press, Ankara, 1997.

[30] A. Carvajal, C. Centeno, R. Watson, E. Bruera. A comprehensive study of psychometric properties of the Edmonton symptom assessment system (ESAS) in Spanish advanced cancer patients. Eur J Cancer, Vol.47, No. 12, 1863-1872, 2011.

*This study has been presented as an oral representation paper $2^{\text {nd }}$ International Conference on Lifelong Education and Leadership in Latvia, 21-23 July, 2016.

This study has been produced from a $\mathrm{PhD}$ thesis called Examination of the Effects of Creativity Training Program Applied to Nursery Students on Their Creative Behaviors. 